\title{
Royal Photographic Society
}

\section{AnNuAl ExhIBITION}

$\mathrm{T}^{\mathrm{o}}$ the man in the street the results of photography are 'pictures' of one sort or another, but mainly intended to be artistic. The eightieth Annual International Exhibition of the Royal Photographic Society usually emphasises in the mind of the visitor this artistic aspect of photography; in the principal gallery, for example, are one hundred and seventy large prints, all of pictorial character, whilst in another room are more than two hundred pictorial lantern slides. Photography is, however, both a science in itself and a good servant ta most other sciences. This exhibition gives a suggestion of its varied problems and applications.

This year, the Eastman Pola light filters seem to be the outstanding example in the exhibition of a photographic problem solved. These filters incorporate a plane polarising material and can be manufactured in sizes large enough to cover camera lenses, and even light sources. They can be used to eliminate the glare, due to surface reflection, from all sorts of objects. Some excellent examples of this are shown, notably some photographs of polished carving and of an oil painting. In the latter, reflections from the brush-marked surface are completely eliminated. Interesting effects are also shown to be produced when one filter is placed over the light source and another, crossed with relation to the first, over the camera. For this exhibit, the Hood Medal has been awarded to Edwin A. Land.

Of educational exhibits is one by P. C. Smethurst illustrating the growth of convection currents from an electric heater immersed in a tank of water. Prints of individual states are shown and a $16 \mathrm{~mm}$. motion film has been made. In another educational film, L. A. Jones shows, by the new Kodachrome colour process, growing crystals photographed through a polarising microscope. A medal has been awarded for this film.

Nor do the technical exhibits of some photographic manufacturers lag behind in explanatory value. The enormous exposure range of modern photographic materials used for ordinary photography is well illustrated by Ilford, Ltd. The same theme is taken by the Eastman Kodak Co. in relation to their automatically controlled reversal process for sub-standard cinematography. Another exhibit by Ilford, Ltd., illustrates the use of special materials for recording atomic disintegration and for mass spectrography.

In colour photography several processes are represented. Agfa Colour, Finlay, Dufay Colour and Kodachrome, of the colour transparency processes, are all represented, whilst for colour prints on paper examples of Tricolour Carbro, Vivex, Raydex and Duxochrome may be seen.

High-speed photography is this year well represented by studies of a football as it is kicked, and a tennis ball at the impact of the racquet-the ball is almost hemispherical. Exposures of 1/100,000 sec. were used for these (K. J. Germeshausen, H. E. Edgerton and H. E. Grier). Another excellent series by A. M. Rothrock and E. C. Buckley records for the first time the injection and combustion of the fuel in a high-speed Diesel engine ; for this a special motion picture camera is used in which the time interval between frames is $1 / 2,500$ sec.

\section{Swelling of Colloids}

$\mathrm{I}^{\mathrm{N}}$ the August number of the Berichte der chemischen Gesellschaft, Prof. H. Staudinger and Herr E. Husemann describe interesting experiments on the behaviour of certain polymerised olefines towards solvents.

It is a remarkable fact that among colloids of high molecular complexity one may find substances apparently identical in composition but possessing very different properties. In a previous paper (1934) it was shown that styrene yields two dissimilar polymers, one of which swells continuously in a given solvent until it dissolves completely, whereas the swelling power of the other is strictly limited. In the latter case, the original form of the polymer is retained after swelling, although the volume may be increased fifty- or hundred-fold, but it remains undissolved. It was found that this insoluble variety with limited swelling power is only produced when small amounts of divinylbenzene are present in the styrene, and the theory was advanced that the soluble form consists of long thread-molecules, whereas in the other case more complex 3-dimensional structures are formed.

Further study has shown that the thread-molecules are long, rigid, elastic structures, not easily deformed but soluble forming viscous solutions. When these threads are linked together by divinylbenzene bridges they may form insoluble 3-dimensional molecules unless the amount of bridging is very minute, when the effect is to produce still longer soluble threads. The products with limited swelling-power are now regarded as tangled, felted mixtures of insoluble bridged products with soluble threads. Complete extraction of the threads by the solvent is prevented by the felting. The investigation of these complex polymers has necessitated the development of a special technique, for which we are mainly indebted to Prof. Staudinger. Methods have already been worked out for the synthesis of a kind of homologous series of colloidal polymers, which are classified according to their molecular dimensions as (1) hemicolloidal, (2) mesocolloidal and (3) eucolloidal polystyrenes with molecular lengths of $20-250,250$ 2500 and 2500-10,000 A. respectively. The authors have made an elaborate study of the polymerisation under varied conditions of pure styrene and divinyi. benzene and of mixtures of these.

In every case the degree of polymerisation was determined by viscosity measurements, and it has been found possible to determine the minimum amount of divinylbenzene required to produce a polymer with limited swelling-power. 